\title{
Construction and Development of Software Platform for Wind-related Researches of High-rise Building
}

\author{
Pei HU ${ }^{1, a}$, Yong QUAN ${ }^{2, b^{*}}$ \\ ${ }^{1,2}$ State Key Laboratory of Disaster Reduction in Civil Engineering, Tongji University, Shanghai \\ 200092, P . R . China \\ afenggongchenghp@126.com, bquanyong@tongji.edu.cn \\ ${ }^{*}$ Corresponding author
}

\begin{abstract}
Keywords: Wind Load, MySQL, Dynamic Web Page Technique.
\end{abstract}
\begin{abstract}
The wind loads are one of the control loads on the high-rise building. Researchers in the wind engineering field have done numerous studies and have made plenty of achievements, which greatly promote the social development. Combining database system and advanced calculation languages, a MySQL-based software platform for wind-related researches of high-rise building is built in the paper. The platform can process the data of wind tunnel tests and calculate both wind loads and responses for structural design, providing guidance to researchers and structure designers.
\end{abstract}

\section{Introduction}

Because of the low frequency and damping, the high-rise buildings are sensitive to the influence of wind, which makes wind loads extremely important to the safety and comfort of the high-rise building.

Numerous studies have been made in the wind engineering field on models of various sizes and shapes, and generate vast amounts of data. Only some specific results were offered to the structure designers, with other data wasted in the lab. Lots of data of field measurement and wind tunnel test in the basic researches are not used either. If there was a software platform to collect, save and process these data for the wind-related researches, it could greatly fill up the deficiency of wind load code and provide guidance to researchers and structure designers.

Database system is a highly effective way to manage vast amounts of data. As a electronic management method, it shortens the time of both inputting and searching information. When new records are to be added, the system will automatically put them in the proper places. And only some simple commands are needed to retrieve the needed information. Database system can also auto-generate forms to list the results. Database system is open to remote access and electronic transportation, which makes the data paperless.

There are several database systems for wind engineering researches in the world. Texas Tech University (TTU) and the United States National Institute of Standards and Technology (NIST) created an aerodynamic database for low building design [1, 2]. Zhou and Kareem built an interactive database of aerodynamic loads [3]. It is comprised of high-frequency base balance measurements on a host of isolated tall building models. And the NataHaz Aerodynamic Loads Database is also put forward to serve the preliminary design of high-rise buildings [4].

Currently there are few wind-tunnel-based or field-measurement-based database systems in China. A MySQL-based software platform for wind-related researches of high-rise building is built by Tongji University and numerous research results are urgently needed to be put in to it. The framework of the platform is represented in the paper. The operation interface of wind load calculation according to load code for the design of building structures (GB 50009-2012) is displayed in the end of the paper.

\section{Framework of Software Platform for Wind-related Researches of High-rise Building}

The software platform is composed of two parts. One is the representation of current results; the 
other is the online calculation platform.

The representation of current results includes data of basic researches, projects and field measurements, offered by the form of figures and tables. These data can be saved directly in the webpage or in the Internet-linked database.

The online calculation platform is proposed to get wind loads for the preliminary design, general wind-induced responses and supplementary calculation for current results. Because the process would probably involve complicated mathematical or mechanical calculation, some advanced structure analysis softwares could be needed to assist the function. The connection of the calculation program and the database system is the key to the calculation platform.

The platform can do two kinds of calculation. Relying on the dynamic web page techniques like MySQL and PHP, it gains the environment, height, shape and frequency of the building from the users, then calculates the loads or responses and shows them online. Or it interpolates the current data to obtain the results. Aerodynamic damping, wind direction and wind profile are all considered in the calculation. Equivalent static wind loads, accelerations, displacements, and pedestrian wind environment are to be obtained.

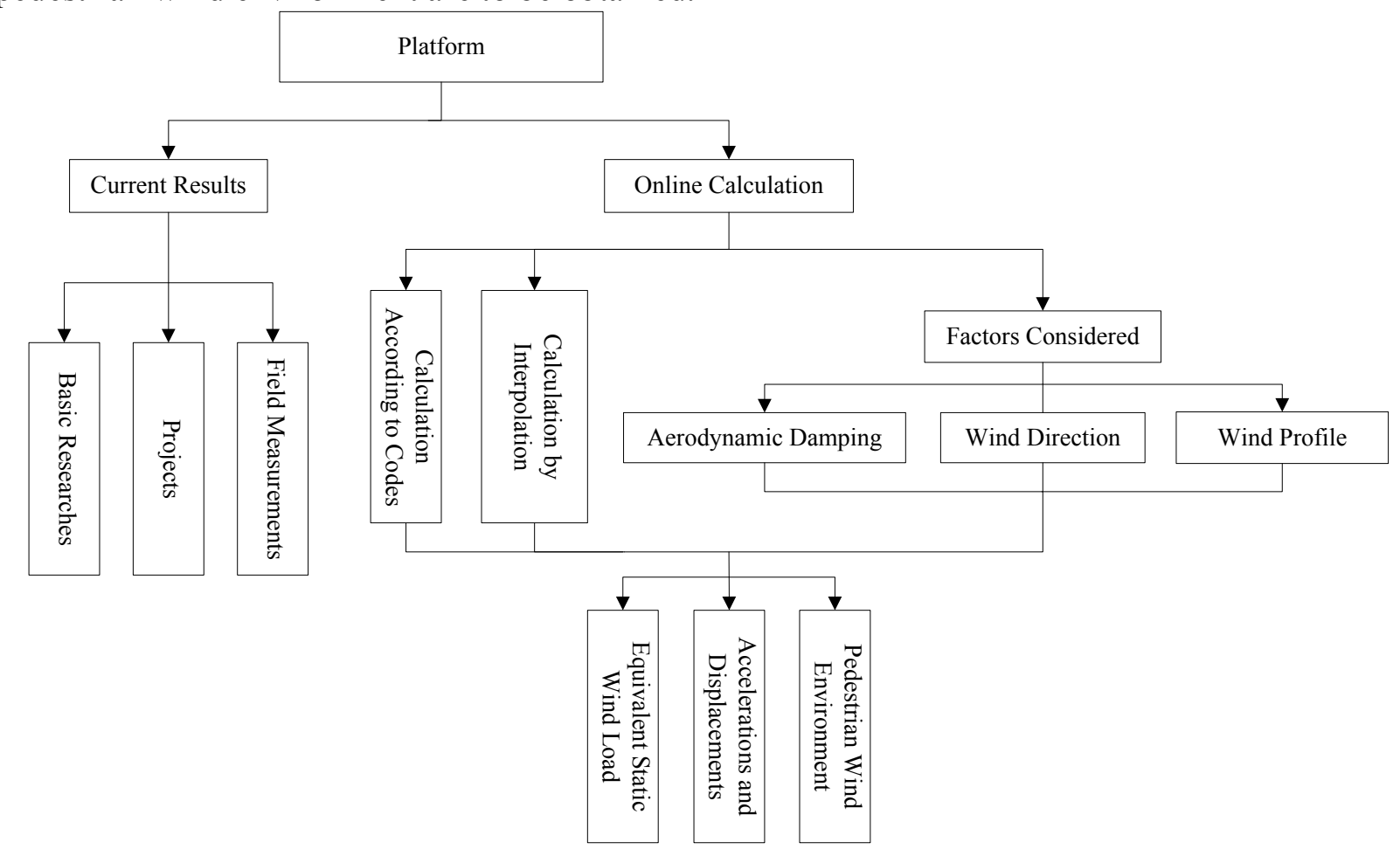

Fig.1 Framework of the Software Platform

Now, the online calculation section of the platform is able to gain characteristic value of the wind loads according to the Load Code for the Design of Building Structures (GB 50009-2012). Further contents will be filled up soon.

\section{Summary}

The framework of the software platform for wind-related researches of high-rise building by Tongji University is introduced in the previous context. Combining MySQL and PHP, it is able to save and sort and process data in the wind engineering researches, and obtains needed wind loads and responses. The software platform will be finally open to the public to offer guidance to researchers and structure designers.

\section{Acknowledgement}

This research was financially supported by the National Natural Science Foundation of China. 


\section{References}

[1]T.C.E. Ho, D. Surry, D. Morrish, et al. The UWO contribution to the NIST aerodynamic database for wind loads on low buildings: Part 1. Archiving format and basic aerodynamic data[J]. Wind Eng. Ind. Aerodyn. 2005 (93) 1-30.

[2]L.M. St. Pierre, G.A. Kopp, D. Surry, et al. Ho. The UWO contribution to the NIST aerodynamic database for wind loads on low buildings: Part 2. Comparison of data with wind load provisions[J]. Wind Eng. Ind. Aerodyn. 2005 (93) 31-59.

[3]Zhou Y, Kijewski T, Kareem A. Aerodynamic Loads on Tall Buildings: Interactive Database[J]. JOURNAL OF STRUCTURAL ENGINEERING. 2003, 3(129): 394-404.

[4]Kwon D, Kijewski T, Kareem A. e-Analysis of High-Rise Buildings Subjected to Wind Loads[J]. JOURNAL OF STRUCTURAL ENGINEERING. 2008, 7(134): 1139-1153. 